\title{
Hereditary interstitial lung diseases manifesting in early childhood in Japan
}

\author{
Takuma Akimoto', Kazutoshi Cho', Itaru Hayasaka', Keita Morioka', Yosuke Kaneshi', Itsuko Furuta², Masafumi Yamada ${ }^{3}$, \\ Tadashi Ariga ${ }^{3}$ and Hisanori Minakami ${ }^{2}$
}

BACKGROUND: Genetic variations associated with interstitial lung diseases (ILD) have not been extensively studied in Japanese infants.

METHODS: Forty-three infants with unexplained lung dysfunction were studied. All 43, 22, and 17 infants underwent analyses of surfactant protein (SP)-C gene (SFTPC) and ATPbinding cassette $A 3$ gene (ABCA3), SP-B gene (SFTPB), and SP-B western blotting, respectively. Two and four underwent assessment of granulocyte macrophage colony-stimulating factor-stimulating phosphorylation of signal transducer and activator of transcription-5 (pSTAT-5) and analyses of FOXF1 gene (FOXF1), respectively.

RESULTS: ILD were diagnosed clinically in nine infants: four, three, and two had interstitial pneumonitis, hereditary pulmonary alveolar proteinosis (hPAP), and alveolar capillary dysplasia with misalignment of pulmonary veins (ACD/MPV), respectively. Genetic variations considered responsible were detected in six (67\%) of the nine infants with ILD: three with hPAP (SFTPC p.Leu45Arg and p.Gln145fs, and ABCA3 p.Arg1583Trp/p.Val1495CysfsX21), two with interstitial pneumonitis (SFTPC p.Lys63Glu and p.Ser72Asn/p.Gly100Ala), and one with ACD/MPV (FOXF1 p.Leu300ArgfsX79). None showed SFTPB mutations or defects in pSTAT-5. The 17 bronchoalveolar lavage or tracheal aspirates contained enough SP-B protein.

CONCLUSION: The SP-C abnormality was most prevalent, and SP-B deficiency was rare in Japanese infants with hereditary ILD.

$\mathrm{P}$ ulmonary diseases that require transient-assisted ventilation, such as respiratory distress syndrome due to lung immaturity, are often encountered by neonatologists working in neonatal intensive care units. However, although rare, there are genetic disorders of lung dysfunction manifesting in early childhood that cannot be explained by prematurity. These pulmonary diseases may be classified into two groups: disorder of alveolar type II epithelial cells (AEC2) and disorder of alveolar macrophages. Disorder of AEC2 includes surfactant protein
(SP)-B deficiency (1), SP-C abnormality (2), and ATP-binding cassette A3 (ABCA3) deficiency (3). Disorder of alveolar macrophages includes abnormality in granulocyte macrophage colony-stimulating factor (GM-CSF) receptor $(4,5)$ and dysfunction of macrophages associated with hypogammaglobulinemia (6). Although considerable overlapping exists, genetic disorders of SP-B and alveolar macrophages are likely to manifest hereditary pulmonary alveolar proteinosis (hPAP), while those of SP-C and ABCA3 are likely to manifest hPAP and/or interstitial pneumonitis (7). In addition, genetic disorders of thyroid transcription factor-1-associated thyroid dysfunction (8) and alveolar capillary dysplasia with misalignment of pulmonary veins (ACD/MPV) (9) often manifest interstitial lung disease (ILD) in early childhood. Thus, genetic abnormalities leading to hereditary ILD (HILD), including hPAP, interstitial pneumonitis, and ACD/MPV, vary.

As ILD is rare and as helpful measures such as high-resolution computed tomography, bronchoalveolar lavage (BAL), and/or lung biopsy are often difficult to perform in small infants, especially in neonates, it may often be difficult for neonatologists to determine the cause of these lung diseases. However, abnormalities in the SP-B gene (SFTPB), SP-C gene (SFTPC), ABCA3 gene (ABCA3), and FOXF1 gene (FOXF1) are known to be responsible for SP-B deficiency, SP-C abnormality, ABCA3 deficiency, and some of ACD/MPV $(7,10)$, respectively. Therefore, analyses of these genes in addition to qualitative analyses of SP-B by western blotting in BAL or tracheal aspirates (11) are helpful to understand the associations between genetic abnormalities and disease phenotypes in these disorders. Assessment of GM-CSF-stimulating phosphorylation of signal transducer and activator of transcription-5 (pSTAT-5) also helps in the diagnosis of alveolar macrophage dysfunction (5).

Accordingly, we developed a new system to aid Japanese neonatologists working in the neonatal intensive care units to search for genetic causes of unexplained lung dysfunction in infants. Here, we report this system and preliminary results of an investigation on the causative genetic abnormalities involved in HILD. 


\section{RESULTS}

During the 2.5-year study period between February 2011 and July 2013, we had a total of 43 consultations from 34 institutions regarding the causes of lung dysfunction in 43 infants. Lung dysfunction manifested within $4 \mathrm{wk}$ after birth in 34 infants (early onset) and 1 mo or later after birth in the remaining nine infants (Table 1). Clinically, nine patients were diagnosed as having ILD (Table 2): four with interstitial pneumonitis were based on findings in biopsied lung specimens except in one patient (case 4 in Table 3) in whom the diagnosis was based on a 2-y history of lung dysfunction, computed tomography, and serum KL-6 $(12,13)$; three with hPAP were based on the results of microscopic BAL examination, and two with ACD/ MPV were based on findings in biopsied or autopsied lung specimen. Others included four diagnoses responsible for or possibly associated with lung dysfunction for each one case: gastroesophageal reflux disease, severe combined immunodeficiency, Kabuki makeup syndrome, and congenital adrenal hypoplasia (14-16). One case with congenital adrenal hypoplasia showed delayed maturation of lung surfactant system due to deficiency of endogenous steroids.

The hPAP was suspected in five cases including three with early onset (cases 1,2 , and 3 in Table 3 ) and two with late onset (case 6 in Table 3 and another case without proven genetic variations) based on computed tomography before the analyses shown in Figure 1. Genetic abnormalities likely to be responsible for lung dysfunction were detected in six of the nine patients with ILD (Tables 2 and 3 and Figure 1). These abnormalities were found during the first-round examination for SFTPC and ABCA3 in five patients (cases $1-5$ in Table 3): SFTPC mutations (five different mutations) in four cases and compound heterozygous $A B C A 3$ mutations in one case (Table 3). Two other compound heterozygous $A B C A 3$

Table 1. Demographic characteristics of 43 patients

\begin{tabular}{lcc}
\hline & Early onset & Late onset \\
\hline Number of patients & $34^{\mathrm{a}}$ & $9^{\mathrm{b}}$ \\
Male sex & $22(65 \%)$ & $5(56 \%)$ \\
Onset of lung dysfunction & $0(0-14) \mathrm{d}$ & $6(3-60)$ mo \\
Gestation length (weeks) & $38(28-41)$ & $40(27-41)$ \\
Apgar score $<7$ (5 min) & $6(18 \%)$ & $0(0 \%)$ \\
Assisted ventilation & $30(88 \%)$ & $5(56 \%)$ \\
iNO & $16(47 \%)$ & $2(22 \%)$ \\
BAL/tracheal aspirates & $15(44 \%)$ & $2(22 \%)$ \\
CT/HRCT & $22(65 \%)$ & $9(100 \%)$ \\
Lung biopsy/autopsy & $6(18 \%)$ & $3(33 \%)$ \\
Poor outcome (death) & $8(24 \%)$ & $2(22 \%)$ \\
\hline
\end{tabular}

Early onset was defined as manifestation of lung dysfunction within 4 wk after birth. Median (range) or number (percentage) is indicated.

$\mathrm{BAL}$, bronchoalveolar lavage; CT/HRCT, computed tomography or high-resolution computed tomography; iNO, inhaled nitric oxide.

aClinically asphyxia and/or meconium aspiration syndrome were suspected in nine infants. bPresumptive clinical diagnosis was interstitial pneumonitis in four cases, respiratory failure associated with immune disorder in two cases, and pulmonary alveolar proteinosis in one case. mutations, i.e., $A B C A 3$ p.Pro73Leu/p.Gly1205Arg and $A B C A 3$ p.Thr761Met/p.Ala1362Val, were detected in two (cases 7 and 8 in Table 3) of the 34 infants without ILD: one full-term infant with p.Pro73Leu/p.Gly1205Arg manifested lung dysfunction immediately after birth, but recovered with transient assisted ventilation only, and another with p.Thr761Met/p.Ala1362Val born at gestational week 27 weighing $778 \mathrm{~g}$ manifested lung dysfunction at 8 mo after birth and is being treated currently with vasodilators and home oxygen.

Twenty-two patients underwent second-round examination (Figure 1). None of the 22 showed SFTPB mutations (Figure 1). The BAL or tracheal aspirates were available for western blotting analysis in 17 of the 22 infants and contained enough SP-B protein. Milky appearance of the BAL with eosinophilic materials on the microscopic examination supported the diagnosis of hPAP in three cases (cases 1,2, and 3 in Table 3 ) but not in two late-onset cases with suspected hPAP (case 6 in Table 3 and another). The pSTAT- 5 was assessed in two infants: one with $A B C A 3$ mutations (case 3 in Table 3 ) and another with suspected hPAP by computed tomography, but not with BAL (case 6 in Table 3). Results indicated normally functioning macrophages in both cases.

Five infants had severe persistent pulmonary hypertension unresponsive to treatment. Four of them underwent analysis of FOXF1. Only case 6 with a diagnosis of ACD/MPV showed an abnormality in FOXF1, i.e., a novel frameshift mutation (Table 3). A female infant with ACD/MPV and birth weight of 3,024 g who died 4 days after birth from lung dysfunction due to pulmonary hypertension exhibited no abnormalities in SFTPC, $A B C A 3$, and SFTPB but did not undergo examination for FOXF1 because her family did not give informed consent to the analysis of FOXF1. This system was helpful to determine causative genetic variations in six (67\%) of the nine patients with ILD and $14.0 \%$ of all 43 referrals.

Family members of five cases underwent genetic testing. Two SFTPC variations (cases 1 and 6) were derived from de novo, and one SFTPC variation (case 4) was inherited from

Table 2. Relationship between clinical diagnosis and genetic variations responsible for lung dysfunction

\begin{tabular}{|c|c|c|c|c|c|c|}
\hline \multirow{2}{*}{$\begin{array}{l}\text { Clinical } \\
\text { diagnosis }\end{array}$} & \multicolumn{6}{|c|}{$\begin{array}{l}\text { Number of infants with abnormality/ } \\
\text { number of infants tested }\end{array}$} \\
\hline & & SFTPC & $A B C A 3$ & SFTPB & pSTAT-5 & FOXF1 \\
\hline $\begin{array}{l}\text { Interstitial } \\
\text { pneumonitis }\end{array}$ & $(n=4)$ & $2 / 4$ & $0 / 4$ & $0 / 0$ & $0 / 0$ & $0 / 0$ \\
\hline hPAP & $(n=3)$ & $2 / 3$ & $1 / 3$ & $0 / 3$ & $0 / 1$ & $0 / 0$ \\
\hline ACD/MPV & $(n=2)$ & $0 / 2$ & $0 / 2$ & $0 / 2$ & $0 / 1$ & $1 / 2$ \\
\hline Others $^{\mathrm{a}}$ & $(n=34)$ & $0 / 34$ & $0 / 34$ & $0 / 17$ & $0 / 0$ & $0 / 2$ \\
\hline Overall & $(n=43)$ & $4 / 43$ & $1 / 43$ & $0 / 22$ & $0 / 2$ & $1 / 4$ \\
\hline \multicolumn{7}{|c|}{$\begin{array}{l}\text { ABCA3 variations seen in two cases (cases } 7 \text { and } 8 \text { in Table } 3 \text { ) were not included in this } \\
\text { table. } \\
\text { ACD/MPV, alveolar capillary dysplasia with misalignment of pulmonary veins; } \mathrm{hPAP} \text {, } \\
\text { hereditary pulmonary alveolar proteinosis. } \\
\text { alncluded four diagnoses responsible for or possibly associated with lung } \\
\text { dysfunction for each one case: gastroesophageal reflux disease, severe combined } \\
\text { immunodeficiency, Kabuki makeup syndrome, and congenital adrenal hypoplasia. }\end{array}$} \\
\hline
\end{tabular}


Table 3. Eight patients in whom genetic variations were found

\begin{tabular}{|c|c|c|c|c|c|c|c|c|c|c|}
\hline Case & BW/GW & Onset & Diagnosis & AV & iNO & Genotype & $\begin{array}{c}\text { SIFT/ } \\
\text { polyphen-2 }\end{array}$ & Origin of variations & Treatment & Outcome \\
\hline 1 & $3,204 / 40$ & $0 d$ & hPAP & Yes & No & $\begin{array}{l}\text { SFTPC c.134T>C: } \\
\text { p.Leu45Arg (het) }\end{array}$ & $\begin{array}{l}\text { Damaging/ } \\
\text { damaging }\end{array}$ & Denovo & $\begin{array}{l}\text { Surfactant, } \\
\text { steroids, } \\
\text { and Hch }\end{array}$ & $\begin{array}{l}\text { Undergoing } \\
\text { treatment, } \\
43 \text { mo }\end{array}$ \\
\hline 2 & $2,600 / 40$ & $6 d$ & hPAP & Yes & No & $\begin{array}{l}\text { SFTPC c.433delC: } \\
\text { p.Gln145fs (het) }\end{array}$ & Not done & Unknownc & $\begin{array}{l}\text { Surfactant, } \\
\text { steroids, } \\
\text { and Hch }\end{array}$ & Died, $77 \mathrm{~d}$ \\
\hline 3 & $3,230 / 40$ & $0 d$ & hPAP & Yes & Yes & $\begin{array}{l}A B C A 3 \\
\text { c.4483_4507del25: } \\
\text { p.Val1495CysfsX21 }\end{array}$ & Not done & Father (asymptomatic) & $\begin{array}{l}\text { Surfactant, } \\
\text { steroids, } \\
\text { and Hch }\end{array}$ & Died, 7 mo \\
\hline 4 & $3,060 / 41$ & $5 \mathrm{mo}$ & $\mathrm{IP}^{\mathrm{a}}$ & No & No & $\begin{array}{l}\text { SFTPC c.187A>G: } \\
\text { p.Lys63Glu (het) }\end{array}$ & $\begin{array}{l}\text { Damaging/ } \\
\text { damaging }\end{array}$ & $\begin{array}{l}\text { Mother (asymptomatic) } \\
\text { and mother's father } \\
\text { (pulmonary fibrosis) }\end{array}$ & $\begin{array}{l}\text { Steroids } \\
\text { and Hch }\end{array}$ & $\begin{array}{l}\text { Undergoing } \\
\text { treatment, } \\
54 \text { mo }\end{array}$ \\
\hline 5 & $3,520 / 38$ & $2 w k$ & IP & Yes & No & $\begin{array}{l}\text { SFTPC c.299G >C: } \\
\text { p.Gly100Ala }\end{array}$ & $\begin{array}{l}\text { Damaging/ } \\
\text { benign }\end{array}$ & Unknownc & $\begin{array}{l}\text { Steroids, } \\
\text { CsA, CPM, } \\
\text { and AZP }\end{array}$ & $\begin{array}{l}\text { Undergoing } \\
\text { treatment, } \\
13 y\end{array}$ \\
\hline 6 & $3,344 / 41$ & $3 \mathrm{mo}$ & $\mathrm{ACD} / \mathrm{MPV}$ & Yes & Yes & $\begin{array}{l}\text { FOXF1 c.899delT: } \\
\text { p.Leu300ArgfsX79 } \\
\text { (het) }\end{array}$ & Not done & Denovo & $\begin{array}{l}\text { Steroids, } \\
\text { vasodilator }\end{array}$ & $\begin{array}{l}\text { Undergoing } \\
\text { treatment, } \\
24 \text { mo }\end{array}$ \\
\hline \multirow[t]{2}{*}{7} & \multirow[t]{2}{*}{$3,194 / 40$} & \multirow[t]{2}{*}{$0 d$} & \multirow[t]{2}{*}{ URD } & \multirow[t]{2}{*}{ Yes } & \multirow[t]{2}{*}{ No } & $\begin{array}{l}\text { ABCA3 c.218C }>\mathrm{T}: \\
\text { p.Pro73Leu }\end{array}$ & $\begin{array}{l}\text { Tolerated/ } \\
\text { benign }^{\mathrm{b}}\end{array}$ & Unknown ${ }^{c}$ & \multirow[t]{2}{*}{ None } & \multirow[t]{2}{*}{ Recovered } \\
\hline & & & & & & $\begin{array}{l}\text { ABCA3 c.3613G >A: } \\
\text { p.Gly1205Arg }\end{array}$ & $\begin{array}{l}\text { Tolerated/ } \\
\text { benign }^{\mathrm{b}}\end{array}$ & & & \\
\hline 8 & $778 / 27$ & $8 \mathrm{mo}$ & CLD, PH & Yes & No & $\begin{array}{l}\text { ABCA3 c. } 2282 \mathrm{C}>\mathrm{T}: \\
\text { p.Thr761Met, }\end{array}$ & $\begin{array}{l}\text { Damaging/ } \\
\text { damaging }\end{array}$ & Mother (asymptomatic) & Vasodilator & $\begin{array}{l}\text { Undergoing } \\
\text { treatment, } \\
17 \mathrm{mo}\end{array}$ \\
\hline
\end{tabular}

ACD/MPV, alveolar capillary dysplasia with misalignment of pulmonary veins; AV, assisted ventilation; AZP, azathioprine; BW/GW, birth weight/gestational week at delivery; CLD, chronic lung disease; CPM, cyclophosphamide; CSA, cyclosporine A; Hch, hydroxychloroquine; hPAP, hereditary pulmonary alveolar proteinosis; iNO, inhaled nitric oxide; IP, interstitial pneumonitis; $\mathrm{PH}$, pumonary hypertension; URD, unexplained respiratory distress.

aDiagnosed based on medical history, computed tomography, and serum KL-6. ${ }^{\mathrm{b} T h r e e ~ o f ~ t h e ~ f o u r ~ v a r i a t i o n s ~ i n ~ c a s e s ~} 7$ and 8 were considered not to be causative for lung dysfunction. The variations at codon 73 and 1,205 in case 7 are not listed in dbSNP or the 1000 Genome Project database. The variation at codon 1,362 in case 8 was identified in more than $1.0 \%$ of Japanese according to the 1000 Genome Project. 'Genetic testing of family members was not performed.

maternal family line (Table 3). Four $A B C A 3$ variations (cases 3 and 8) were inherited from both parents.

Clinical factors were compared between 6 and 37 infants with and without gene mutations, respectively (Table 4). Neither a low birth weight $(<2,500 \mathrm{~g})$ and Apgar score $<7$ at $5 \mathrm{~min}$, nor timing of onset of lung dysfunction differentiated these cases. However, the frequencies of infants with a positive BAL test result assisted ventilation $>30$ days, and histologically proven ILD were significantly higher in the former six patients than that in the latter 37 patients.

\section{DISCUSSION}

The system presented here was useful for determination of genetic variations that were possibly causative for ILD in six (67\%) of the nine patients and $14 \%$ of all 43 referrals with severe and unexplained lung dysfunction. These six HILD cases included four cases of SP-C abnormality, one case of ABCA3 deficiency, and one case of FOXF1 abnormality. None of these cases was affected by SP-B deficiency. As no infants had hypothyroidism, examination of thyroid transcription factor- 1 abnormality was not performed in this study. However, as infants with thyroid transcription factor-1 abnormality (NKX2-1 mutation) do not necessarily have hypothyroidism (17), it is possible that some infants had thyroid transcription factor-1 abnormality in this study population.

Among the 12 genetic variations detected in the eight cases (cases 1-8 in Table 3), two in cases 1 and 6 were reported previously $(18,19)$. To our knowledge, 10 other mutations in six cases (cases 2-5, 7, and 8) have not been reported to date, i.e., four SFTPC mutations of heterozygous p.Gln145fs, heterozygous p.Lys63Glu, p.Ser72Asn, and p.Gly100Ala, and six $A B C A 3$ mutations of p.Arg1583Trp, p.Val1495CysfsX21, p.Pro73Leu, p.Gly1205Arg, p.Thr761Met, and p.Ala1362Val. The pro-SP$\mathrm{C}$ amino acids of codons 63,72 , and 100 are well preserved in many mammals and two SFTPC mutations, i.e., p.Lys63Glu (case 4) and p.Ser72Asn (case 5), were judged as "damaging" with both SIFT and polyphen-2. Although p.Gly100Ala was "damaging" with polyphen-2 only, but not with SIFT, mutations of p.Gly100Val and p.Gly100Ser are associated with lung dysfunction $(20,21)$. Frameshift mutations were detected in case 2 


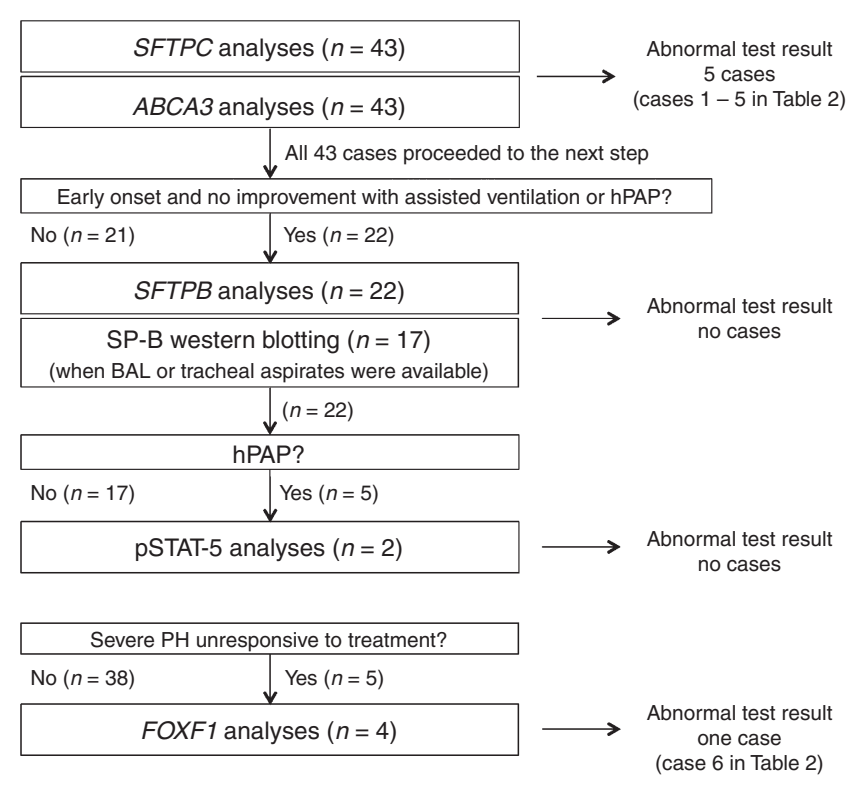

Figure 1. Flow diagram showing patient selection criteria for various examinations and test results. All 43 patients underwent analyses of SFTPC and $A B C A 3$ in the first step. Among 30 patients with early onset requiring assisted ventilation, 20 did not exhibit improvement in the respiratory status. These 20 and 2 with late onset and suspected hPAP (case 6 and another) underwent second-round examination for SFTPB. In 17 of the 22 patients, BAL or tracheal aspirates were available for SP-B western blotting analysis (Table 1). Milky appearance of the BAL with eosinophilic materials on the microscopic examination supported the diagnosis of hPAP in three cases (cases 1, 2, and 3), but not in two late-onset cases with suspected hPAP (case 6 and another). Two cases (cases 3 and 6 ) underwent assessment of pSTAT- 5 because case 3 was not identified to have $A B C A 3$ mutation at that time and because case 6 was strongly suggested to be hPAP on computed tomography. Four of five patients with severe pulmonary hypertension unresponsive to treatment underwent analysis of FOXF1. One who died from pulmonary hypertension $(\mathrm{PH})$ and $\mathrm{ACD} / \mathrm{MPV}$ after $4 \mathrm{~d}$ of birth did not undergo analysis of FOXF1. ACD/MPV, alveolar capillary dysplasia with misalignment of pulmonary veins; BAL, bronchoalveolar lavage; hPAP, hereditary pulmonary alveolar proteinosis; SP-B, surfactant protein B.

(SFTPC p.Gln145fs) and case 3 (ABCA3 p.Val1495CysfsX21), and such mutations can be associated with abnormal protein function. SFTPC p.His142fs was reported in a neonate with SP-C abnormality (22). The p.Arg1583Trp in case 3 was judged as "damaging" with both SIFT and polyphen-2. Therefore, we speculated that these six mutations were responsible for ILD in the four infants. Whether the three variations in cases 7 and 8 except $A B C A 3$ p.Thr761Met were causative for lung dysfunction is undetermined. The $A B C A 3$ p.Thr761Met in case 8 was judged as "damaging" with both SIFT and polyphen-2 occurring in one in 6,500 European and Americans according to the Exome Sequencing Project. Thus, the $A B C A 3$ p.Thr761Met may be responsible for lung dysfunction in case 8 . More than 30 different mutations of SFTPC) $(2,7,18,20-27$ and more than 70 different mutations of $A B C A 3)(3,7,21,28-30$ have been reported in association with lung dysfunction. Thus, the first-round examination for SFTPC and $A B C A 3$ efficiently detected genetic abnormalities in five of the nine patients with ILD in this study.

The SP-B deficiency is one of the major causes of SP dysfunction disorders in Western countries: of 25 cases of hereditary SP dysfunction disorder in the UK, six (24\%), seven
Table 4. Comparison of demographic characteristics between 6 and 37 patients

\begin{tabular}{|c|c|c|c|}
\hline & Six patients ${ }^{\mathrm{a}}$ & $\begin{array}{c}\text { Thirty-seven } \\
\text { patients }\end{array}$ & $P$ value \\
\hline Preterm birth (<37 wk) & $0(0.0 \%)$ & $6(16 \%)$ & 0.3813 \\
\hline Birth weight $<2,500 \mathrm{~g}$ & $0(0.0 \%)$ & $8(22 \%)$ & 0.2662 \\
\hline Male sex & $3(50 \%)$ & $24(65 \%)$ & 0.3941 \\
\hline Apgar score $<7$ at $5 \mathrm{~min}$ & $0(0.0 \%)$ & $7(19 \%)$ & 0.3195 \\
\hline \multicolumn{4}{|l|}{ Timing of onset } \\
\hline Immediately after birth & $2(33 \%)$ & $27(73 \%)$ & 0.0767 \\
\hline Within 4 wk after birth & $4(67 \%)$ & $30(81 \%)$ & 0.3686 \\
\hline iNO & $2(33 \%)$ & $16(43 \%)$ & 0.5034 \\
\hline Assisted ventilation & $5(83 \%)$ & $30(81 \%)$ & 0.6922 \\
\hline More than $30 \mathrm{~d}$ & $5(83 \%)$ & $10(27 \%)$ & 0.0146 \\
\hline Positive for PAP on BAL & $3(50 \%)$ & $0(0.0 \%)$ & 0.0016 \\
\hline Histologically proven ILD & $3(50 \%)$ & $3(8.1 \%)$ & 0.0272 \\
\hline \multicolumn{4}{|c|}{$\begin{array}{l}\text { BAL, bronchoalveolar lavage; ILD, interstitial lung disease; iNO, inhaled nitric oxide; PAP, } \\
\text { pulmonary alveolar proteinosis. } \\
\text { aSix infants in whom causative genetic abnormalities were detected, not including two } \\
\text { cases (cases } 7 \text { and } 8 \text { in Table } 3 \text { ) because it was uncertain whether detected variations } \\
\text { were causative for their lung dysfunction. }\end{array}$} \\
\hline
\end{tabular}

(28\%), and 12 (48\%) were SP-B deficiency, SP-C abnormality, and $A B C A 3$ deficiency, respectively (21). In those with SP-B deficiency, more than 30 SFTPB mutations were reported) $(1,3,7,11,21,31-33)$. However, none of the 22 cases tested had $S F T P B$ mutations in this study (Table 2 and Figure 1). There have been no reports of patients with diagnosis of SP-B deficiency in Japanese patients to date (34). The 121ins2 mutation responsible for SP-B deficiency, estimated to occur in $\sim 1$ in 1,000 Americans, is not found in Korean or South African populations (31). The ABCA3 deficiency accounts for $48 \%$ $(12 / 25)$ of SP dysfunction disorders in the UK, while its deficiency was seen in only one of the six cases of HILD in this study. Thus, it was suggested that there are ethnic differences in the prevalence rates of SP-B deficiency and ABCA3 deficiency.

There were two patients with ACD/MPV in this study, and one of them had a FOXF1 mutation (heterozygousp.Leu300ArgfsX79) which is listed in a recent report (19). Approximately $80 \%$ of $\mathrm{ACD} / \mathrm{MPV}$ cases have anomalies of other organs, particularly of the cardiovascular, gastrointestinal, and genitourinary systems (35). The previous study (19) substantiates the suggestion that mutations in FOXF1 lead to manifestation of ACD/MPV and that this transcription factor is involved in development of the pulmonary, cardiovascular, gastrointestinal, and genitourinary systems. Although rare, late presentation has been reported $(36,37)$ with affected patients typically developing lung dysfunction and pulmonary hypertension a few hours after birth. Our case 6 with late onset at 3 mo after birth who has survived until age 2 y had no anomalies in other organs and is currently being treated with vasodilators and home oxygen. Another case with $\mathrm{ACD} / \mathrm{MPV}$ in whom the analysis of FOXF1 was not given exhibited a typical course and died $4 \mathrm{~d}$ after birth.

As our E-mail Network of Neonatologists covers almost all neonatologists who treat severe cases in neonatal intensive care 
units in Japan, most infants with severe and unexplained lung dysfunction may have been referred to us. However, it was possible that some neonates who died very early were not referred to us. Four of the nine infants with ILD including one with ACD/MPV but not with FOXF1 analysis were born after the announcement of this system in February 2011, and three of the four were identified to have genetic abnormalities (cases 2 , 3 , and 6). As there were $\sim 2,625,000$ neonates during the $2.5-y$ study period in Japan, the prevalence of HILD was estimated to be at least one in $875,000(3 / 2,625,000)$.

Neither clinical factors, such as a low Apgar score and timing of onset of lung dysfunction, nor use of inhaled nitric oxide differentiated HILD from patients with unproven gene mutations in this study. However, in patients in UK, respiratory distress at birth was the presenting symptom in all six infants with $S F T P B$ mutations and in 10 of 12 infants with confirmed $A B C A 3$ mutations, while patients with SFTPC mutations were more likely to present with chronic cough, failure to thrive, or oxygen dependency during later stages (24). Indeed, three of the four patients with SFTPC mutations manifested lung dysfunction later, i.e., $6 \mathrm{~d}, 2 \mathrm{wk}$, and $5 \mathrm{mo}$ after birth, while one infant with $A B C A 3$ mutations showed lung dysfunction immediately after birth in this study. In addition, gene mutations were efficiently detected in infants with assisted ventilation for more than $30 \mathrm{~d}$, positive findings for pulmonary alveolar proteinosis in the BAL, and/or histologically confirmed ILD (Table 4). This information may be useful for clinicians in searching for specific mutations responsible for lung dysfunction.

In conclusion, 43 infants with severe and unexplained lung dysfunction were referred to us over a $2.5-y$ study period. Nine (21\%) of these patients were diagnosed clinically as having ILD. Mutations of SFTPC in four cases, $A B C A 3$ in one case, and FOXF1 in one case were considered to be responsible for ILD in six of the nine patients. None of 22 patients including 20 with early onset and no improvement of lung dysfunction and two with late onset and suspected hPAP had SFTPB mutations. These observations suggested that the prevalence of HILD is at least 1 per 875,000 Japanese infants, the SP-C abnormality is the most prevalent aberration, and SP-B deficiency is rare among Japanese infants with ILD.

\footnotetext{
METHODS

The present system was announced to Japanese neonatologists via an E-mail Network of Neonatologists in February 2011 after receiving approval from the Institutional Review Board of the Hokkaido University Graduate School of Medicine. Collaboration with the Japan Society for Premature and Newborn Medicine was begun in February 2012 to facilitate collection of cases with severe and unexplained lung dysfunction: the Japan Society for Premature and Newborn Medicine announced 3,300 neonatologists four times annually since February 2012 to register prospectively patients with unexplained sustained respiratory distress due to genetic disorder or unknown origin, and not patients with respiratory failure due to known reasons including infection, congenital heart disease, systemic bone disease, neuromuscular disease, malformations, pulmonary hypertension after birth asphyxia, and bronchopulmonary dysplasia caused by prematurity. Most Japanese neonatologists were members of the Japan Society for Premature and Newborn Medicine, and the members were working at $\sim 90 \%$ of all facilities with neonatal intensive care units in Japan.
}

\section{Patients}

All of the 43 families provided detailed clinical information, and blood samples were obtained for genetic analysis with written informed consent. Our system offered a stepwise laboratory examination for patients with unexplained lung dysfunction (Figure 1). All 43 cases underwent first-round examination including analysis of SFTPC and $A B C A 3$. Then, 22 cases including 20 with early onset requiring assisted ventilation and no improvement of respiratory status and two cases with late onset and suspected hPAP underwent second-round examination. Analysis of SFTPB was performed in these 22 cases. In 17 of them, the BAL or tracheal aspirates were available for SP-B western blotting analysis and microscopic examination. Among the 22 cases, two proceeded to third-round examination of pSTAT-5. Finally, four of five patients with severe persistent pulmonary hypertension unresponsive to treatment underwent analysis of FOXF1.

\section{Analyses of the SFTPC, ABCA3, SFTPB, and FOXF1 Genes}

Genomic DNA was extracted from peripheral blood using a QIAamp DNA Blood Mini Kit (Qiagen, Hilden, Germany). PCR primers reported previously were used for SFTPC (23). PCR primers for $S F T P B, A B C A 3$, and FOXF1 were designed using Primer3 (38) to amplify all of the coding exons and their exon-intron boundaries. PCR was performed using a GeneAmp PCR System 2700 (Applied Biosystems, Foster, CA) with AmpliTaq Gold 360 PCR Master Mix (Life Technologies, Carlsbad, CA) in a 20 - $\mu$ l reaction mixture containing $40 \mathrm{ng}$ of DNA template, and $0.5 \mu \mathrm{mol} / \mathrm{l}$ of each primer. PCR conditions were variable for each amplicon: incubation at $95^{\circ} \mathrm{C}$ for $10 \mathrm{~min}$ followed by 40 cycles of three or two steps (depending on primer) of: (i) denaturation at $95^{\circ} \mathrm{C}$ for $30 \mathrm{~s}$, annealing at $58-60^{\circ} \mathrm{C}$ for $30 \mathrm{~s}$, and extension at $72^{\circ} \mathrm{C}$ for $1 \mathrm{~min}$ or (ii) denaturation at $95^{\circ} \mathrm{C}$ for $30 \mathrm{~s}$ and extension at $63{ }^{\circ} \mathrm{C}$ for $1 \mathrm{~min}$ with a final extension at $72{ }^{\circ} \mathrm{C}$ for $10 \mathrm{~min}$. PCR products were analyzed by electrophoresis using 2.0\% agarose gels and purified with a QIAquick Gel Extraction Kit (Qiagen). Purified products were subjected to nucleotide sequence analysis by a commercial sequencing service (FASMAC, Kanagawa, Japan). Nucleotide sequences were compared with the reported reference sequences: NM_003018.3 (SFTPC), NM_001089.2 (ABCA3), NM_198843.2 (SFTPB), or NM_001451.2 (FOXF1).

\section{SP-B Western Blotting Analyses of BAL or Tracheal Aspirates}

BAL and tracheal aspirates were used without centrifugation and lipid extraction. Samples corrected for protein concentration were suspended in Laemmli sample buffer. Tricine/sodium dodecyl sulfate polyacrylamide gel electrophoresis was performed as reported previously (39), and aliquots of $20 \mu \mathrm{g}$ of protein per lane were separated on $16 \%$ polyacrylamide gels. The proteins were transferred onto polyvinylidene fluoride membranes and examined by western blotting. Polyclonal antibody to human SP-B (Hycult, Uden, The Netherlands) was used as the primary antibody at a concentration of 1:50, and horseradish peroxidase-conjugated antirabbit immunoglobulin G (GE Healthcare, Little Chalfont, UK) was used as the secondary antibody at a concentration of 1:1,000. The blots were then visualized using Immobilon western chemiluminescent HRP substrate (Millipore, Billerica, MA).

\section{Analyses of GM-CSF-Induced Phosphorylation of pSTAT-5}

Peripheral blood mononuclear cells were suspended in Roswell Park Memorial Institute medium 10\% fetal bovine serum at a concentration of $1 \times 10^{6}$ cells per $\mathrm{ml}$ and were incubated in the presence or absence of $20 \mathrm{ng} / \mathrm{ml} \mathrm{GM}$-CSF for $15 \mathrm{~min}$. Whole cell lysates were prepared by homogenization in $1 \times$ sodium dodecyl sulfate sample buffer, separated by glycine/sodium dodecyl sulfate polyacrylamide gel electrophoresis according to the standard procedure, and transferred onto polyvinylidene fluoride membranes. Anti-STAT-5 (pY694) antibody (BD, San Diego, CA) was used at a final concentration of $0.5 \mu \mathrm{g} / \mathrm{ml}$, and antiactin antibody (Sigma, St Louis, MO) was used at a final concentration of 1 $\mu \mathrm{g} / \mathrm{ml}$ as a loading control.

\section{ACKNOWLEDGMENTS}

We thank all of the neonatologists who provided information and materials dealt with in this study. 


\section{STATEMENT OF FINANCIAL SUPPORT}

This study was partly supported by a grant for "Rare lung diseases (pulmonary alveolar proteinosis, congenital interstitial lung disease and hereditary hemorrhagic telangiectasia) (H24-Nanchitou (Nanchi)-Ippan-035)" from the Ministry of Health, Labour and Welfare, Japan.

Disclosure: None of the authors have any conflicts of interest.

\section{REFERENCES}

1. Nogee LM, de Mello DE, Dehner LP, Colten HR. Brief report: deficiency of pulmonary surfactant protein B in congenital alveolar proteinosis. N Engl J Med 1993;328:406-10.

2. Nogee LM, Dunbar AE 3rd, Wert SE, Askin F, Hamvas A, Whitsett JA. A mutation in the surfactant protein $\mathrm{C}$ gene associated with familial interstitial lung disease. N Engl J Med 2001;344:573-9.

3. Shulenin S, Nogee LM, Annilo T, Wert SE, Whitsett JA, Dean M. ABCA3 gene mutations in newborns with fatal surfactant deficiency. N Engl J Med 2004;350:1296-303.

4. Dirksen U, Nishinakamura R, Groneck P, et al. Human pulmonary alveolar proteinosis associated with a defect in GM-CSF/IL-3/IL-5 receptor common beta chain expression. J Clin Invest 1997;100:2211-7.

5. Suzuki T, Sakagami T, Rubin BK, et al. Familial pulmonary alveolar proteinosis caused by mutations in CSF2RA. J Exp Med 2008;205:2703-10.

6. Cho K, Nakata K, Ariga T, et al. Successful treatment of congenital pulmonary alveolar proteinosis with intravenous immunoglobulin $\mathrm{G}$ administration. Respirology 2006;11:Suppl:S74-7.

7. Wert SE, Whitsett JA, Nogee LM. Genetic disorders of surfactant dysfunction. Pediatr Dev Pathol 2009;12:253-74.

8. Guillot L, Carré A, Szinnai G, et al. NKX2-1 mutations leading to surfactant protein promoter dysregulation cause interstitial lung disease in "Brain-Lung-Thyroid Syndrome". Hum Mutat 2010;31:E1146-62.

9. Bishop NB, Stankiewicz P, Steinhorn RH. Alveolar capillary dysplasia. Am J Respir Crit Care Med 2011;184:172-9.

10. Stankiewicz P, Sen P, Bhatt SS, et al. Genomic and genic deletions of the FOX gene cluster on 16q24.1 and inactivating mutations of FOXF1 cause alveolar capillary dysplasia and other malformations. Am J Hum Genet 2009;84:780-91.

11. Wegner DJ, Hertzberg T, Heins HB, et al. A major deletion in the surfactant protein-B gene causing lethal respiratory distress. Acta Paediatr 2007;96:516-20.

12. Al-Salmi QA, Walter JN, Colasurdo GN, et al. Serum KL-6 and surfactant proteins A and D in pediatric interstitial lung disease. Chest 2005;127: 403-7.

13. Doan ML, Elidemir O, Dishop MK, et al. Serum KL-6 differentiates neuroendocrine cell hyperplasia of infancy from the inborn errors of surfactant metabolism. Thorax 2009;64:677-81.

14. Herbst JJ, Minton SD, Book LS. Gastroesophageal reflux causing respiratory distress and apnea in newborn infants. J Pediatr 1979;95(5 Pt 1): 763-8.

15. Adam MP, Hudgins L. Kabuki syndrome: a review. Clin Genet 2005;67: 209-19.

16. Deerojanawong J, Chang AB, Eng PA, Robertson CF, Kemp AS. Pulmonary diseases in children with severe combined immune deficiency and DiGeorge syndrome. Pediatr Pulmonol 1997;24:324-30.

17. Carré A, Szinnai G, Castanet M, et al. Five new TTF1/NKX2.1 mutations in brain-lung-thyroid syndrome: rescue by PAX8 synergism in one case. Hum Mol Genet 2009;18:2266-76.

18. Poterjoy BS, Vibert Y, Sola-Visner M, McGowan J, Visner G, Nogee LM. Neonatal respiratory failure due to a novel mutation in the surfactant protein C gene. J Perinatol 2010;30:151-3.
19. Sen P, Yang Y, Navarro C, et al. Novel FOXF1 mutations in sporadic and familial cases of alveolar capillary dysplasia with misaligned pulmonary veins imply a role for its DNA binding domain. Hum Mutat 2013;34:801-11.

20. Nogee LM, Dunbar AE 3rd, Wert S, Askin F, Hamvas A, Whitsett JA. Mutations in the surfactant protein $\mathrm{C}$ gene associated with interstitial lung disease. Chest 2002;121:Suppl 3:20S-1S.

21. Ono S, Tanaka T, Ishida M, et al. Surfactant protein C G100S mutation causes familial pulmonary fibrosis in Japanese kindred. Eur Respir J 2011;38:861-9.

22. Guillot L, Epaud R, Thouvenin G, et al. New surfactant protein C gene mutations associated with diffuse lung disease. J Med Genet 2009;46: $490-4$.

23. Lawson WE, Grant SW, Ambrosini V, et al. Genetic mutations in surfactant protein $\mathrm{C}$ are a rare cause of sporadic cases of IPF. Thorax 2004;59:977-80.

24. Turcu S, Ashton E, Jenkins L, Gupta A, Mok Q. Genetic testing in children with surfactant dysfunction. Arch Dis Child 2013;98:490-5.

25. Thouvenin G, Abou Taam R, Flamein F, et al. Characteristics of disorders associated with genetic mutations of surfactant protein C. Arch Dis Child 2010;95:449-54.

26. Baekvad-Hansen M, Nordestgaard BG, Tybjaerg-Hansen A, Dahl M. Two novel mutations in surfactant protein- $\mathrm{C}$, lung function and obstructive lung disease. Respir Med 2010;104:418-25.

27. Hamvas A. Inherited surfactant protein-B deficiency and surfactant protein-C associated disease: clinical features and evaluation. Semin Perinatol 2006;30:316-26.

28. Bullard JE, Wert SE, Whitsett JA, Dean M, Nogee LM. ABCA3 mutations associated with pediatric interstitial lung disease. Am J Respir Crit Care Med 2005;172:1026-31.

29. Flamein F, Riffault L, Muselet-Charlier C, et al. Molecular and cellular characteristics of $\mathrm{ABCA} 3$ mutations associated with diffuse parenchymal lung diseases in children. Hum Mol Genet 2012;21:765-75.

30. Brasch F, Schimanski S, Mühlfeld C, et al. Alteration of the pulmonary surfactant system in full-term infants with hereditary ABCA3 deficiency. Am J Respir Crit Care Med 2006;174:571-80.

31. Gower WA, Nogee LM. Surfactant dysfunction. Paediatr Respir Rev 2011;12:223-9.

32. Hartl D, Griese M. Interstitial lung disease in children - genetic background and associated phenotypes. Respir Res 2005;6:32.

33. Nogee LM, Wert SE, Proffit SA, Hull WM, Whitsett JA. Allelic heterogeneity in hereditary surfactant protein B (SP-B) deficiency. Am J Respir Crit Care Med 2000;161(3 Pt 1):973-81.

34. Shimizu H, Arakawa H, Lee GH, Obata M, Ogawa Y. Report of congenital alveolar proteinosis and surfactant protein B deficiency in Japan: Japan Neonatal Surveillance Project. J Jpn Soc Premature Newborn Med 2003;15:107-10

35. Sen P, Thakur N, Stockton DW, Langston C, Bejjani BA. Expanding the phenotype of alveolar capillary dysplasia (ACD). J Pediatr 2004; 145:646-51.

36. Ahmed S, Ackerman V, Faught P, Langston C. Profound hypoxemia and pulmonary hypertension in a 7-month-old infant: late presentation of alveolar capillary dysplasia. Pediatr Crit Care Med 2008;9:e43-6.

37. Licht C, Schickendantz S, Sreeram N, et al. Prolonged survival in alveolar capillary dysplasia syndrome. Eur J Pediatr 2004;163:181-2.

38. Rozen S, Skaletsky H. Primer3 on the WWW for general users and for biologist programmers. Methods Mol Biol 2000;132:365-86.

39. Schägger H, von Jagow G. Tricine-sodium dodecyl sulfate-polyacrylamide gel electrophoresis for the separation of proteins in the range from 1 to $100 \mathrm{kDa}$. Anal Biochem 1987;166:368-79. 